\title{
Distillation Time Changes Oregano Essential Oil Yields and Composition but Not the Antioxidant or Antimicrobial Activities
}

\author{
Valtcho D. Zheljazkov ${ }^{1}$ \\ University of Wyoming, Sheridan Research and Extension Center, 663 Wyarno \\ Road, Sheridan, WY 82801
}

Tess Astatkie

Nova Scotia Agricultural College, Department of Engineering, 50 Pictou

Road, P.O. Box 550, Truro, Nova Scotia B2N 5E3, Canada

\author{
Vicki Schlegel \\ University of Nebraska-Lincoln, Department of Food Science and Technology, \\ 326 Food Technology Complex, Lincoln, NE 68583 \\ Additional index words. Origanum vulgare, steam distillation, carvacrol, antileishmanial \\ activity, antimalarial activity, cytotoxicity
}

\begin{abstract}
Oregano (Origanum vulgare L.) is an important medicinal, culinary, and essential oil plant. Oregano essential oil is extracted from either leaves or shoots through steam distillation. Researchers and industry in various countries reported different distillation times (DTs) for oregano; however, there are no reports on optimum DT. This study evaluated the effect of DT $(1.25,2.5,5,10,20,40,80,160,240,360 \mathrm{~min})$ on essential oil yield, composition, and antioxidant activity of the oregano essential oil. In general, the concentration of the low boiling essential oil constituents (alpha-thujene, alpha-pinene, camphene, l-octen-3ol, myrcene, alpha-terpinene, paracymene, beta-phellandrene/limonene, gamma-terpinene, cis-sabinene hydrate, terpinolene) were highest at the shortest DT (1.25 or $2.5 \mathrm{~min}$ ), reduced with increasing DT up to $40 \mathrm{~min}$, and then stayed the same. However, the concentration of the major oil constituent, carvacrol, was lowest at the shortest DT of $1.25 \mathrm{~min}(18 \%)$ and increased steadily with increasing DT up to $40 \mathrm{~min}$, where it leveled at $80 \%$ to $82 \%$. The concentration of other higher boiling constituents (borneol, 4-terpineol, beta-bisabolene, beta-caryophylenne) was maximum at 5 to 20 min DT. Maximum yield of the low boiling constituents was achieved at relatively short DT, at $\approx 20 \mathrm{~min} D T$, and peaked again at $240 \mathrm{~min}$ DT. Maximum yields of alpha-terpinene, beta-phellandrene/limonene, and gamma-terpinene were reached at $240 \mathrm{~min}$ DT. Maximum yields of paracymene cis-sabinene hydrate, terpinolene, and transsabinene hydrate were also achieved at $240 \mathrm{~min}$ DT, but yields at $20 \mathrm{~min}$ DT were not different. Yields of borneol, 4-terpinenol, carvacrol, beta-caryophyllene, and beta-bisabolene also were highest at $240 \mathrm{~min}$ DT. Distillation time at 20,80 , or $360 \mathrm{~min}$ did not alter antioxidant or antimicrobial activity of oregano oil. The relationship between the concentration and yield of the constituents with DT was adequately modeled by the asymptotic and Michaelis-Menten nonlinear regression models, respectively. Results demonstrated that 1) DT can be used to obtain oregano essential oil with differential composition; 2) maximum essential oil yield of steam-distilled oregano leaves could be obtained at $240 \mathrm{~min}$ DT; and 3) reports on oregano essential oil yield and composition using different DTs may not be comparable. Results from this study will aid in comparing published reports on oregano essential oil that used different lengths of DT.
\end{abstract}

Oregano (Origanum vulgare L.) is a wellknown medicinal, culinary, and essential oil

\footnotetext{
Received for publication 12 Mar. 2012. Accepted for publication 2 Apr. 2012.

This research was funded by the University of Wyoming startup funding awarded to Dr. Zheljazkov. We thank Mrs. Adrienne O. Tatman for her help with the extraction of the oregano oil. We thank Dr. Charles L. Cantrell and the National Center for Natural Products Research for the antimicrobial assays.

${ }^{1}$ To whom reprint requests should be addressed; e-mailvveliazk@uwyo.edu; valtcho.pubs@gmail. com.
}

plant that has been used as medicinal plant since ancient times in the Mediterranean region (Stojanov, 1973). Indeed, the plant, the plant extract, and the essential oil have shown antimicrobial (Busatta et al., 2007; Ntzimani et al., 2011; Roussenova, 2011) and antioxidant (Karakaya et al., 2011; Yanishlieva et al., 2006) activity. Recent study demonstrated that dietary addition of oregano leaves to lactating cows feed increased milk fat concentration, milk yield, and decreased rumen methane production (Tekippe et al., 2011).

Oregano is grown as an essential crop in several countries in southeastern Europe and in the Mediterranean region such as Bulgaria,
Romania, Greece, and Turkey (Atanassova and Nedkov, 2004). Oregano essential oil is used in the food industry, in cosmetics, and in other consumer products. The essential oil traditionally is extracted either from the leaves or the shoots through steam distillation (Kula et al., 2007; Topalov, 1962), although other extraction methods such as hydrodistillation, $\mathrm{CO}_{2}$ extraction, and supercritical fluid extraction have been reported (Gaspar and Leeke, 2004; Karakaya et al., 2011; Ondarza and Sánchez, 1990). Because the essential oil composition influences its biological activity (Karakaya et al., 2011), the essential oil yield (content) is important with respect to the economics of production.

Oregano essential oil yield and composition are influenced by various factors such as origin and chemotype (Bisht et al., 2009; Farías et al., 2010; Kula et al., 2007), growing conditions (Azizi et al., 2009), fertilization (Azizi et al., 2009; Sotiropoulou and Karamanos, 2010), and method of extraction (Gaspar and Leeke, 2004; Karakaya et al., 2011; Ondarza and Sánchez, 1990). Currently, there is no detailed report on the effect of DT on oregano essential oil yield and composition. We therefore hypothesized that the length of the DT will have a significant effect on oregano essential oil yield, composition, and antioxidant activity. The objective of this study was to evaluate the effect of DT $(1.25,2.5,5,10,20,40,80$, 160,240 , and $360 \mathrm{~min}$ ) on essential oil yield, composition, and on the antioxidant activity of the oregano essential oil and model the relationship between essential oil yield and composition with DT using nonlinear regression models.

\section{Materials and Methods}

Steam distillation and distillation times. Bulk certified dried leaves of Origanum vulgare L. were purchased from Starwest Botanicals (Rancho Cordova, CA). The experiment was carried out at the University of Wyoming Sheridan Research and Extension Center in 2011. Sample amount for all distillations was $250 \mathrm{~g}$ of dried oregano leaves. Oregano essential oil was extracted through the traditional steam distillation method using 2-L steam distillation units, as described previously for peppermint and spearmint (Zheljazkov and Astatkie, 2011; Zheljazkov et al., 2010).

The following DTs were studied: $1.25 \mathrm{~min}$, $2.5 \mathrm{~min}, 5 \mathrm{~min}, 10 \mathrm{~min}, 20 \mathrm{~min}, 40 \mathrm{~min}, 80 \mathrm{~min}$, $160 \mathrm{~min}, 240 \mathrm{~min}$, and $360 \mathrm{~min}$, all in three replicates. These DTs were measured from the beginning of the distillation, when the first drop of essential oil was deposited until the end of the distillation, when the heating was turned off, the vapor pressure reduced, and the Florentine vessel (a separator) removed from the apparatus. The oil was measured on an analytical balance and kept in a freezer at $-5{ }^{\circ} \mathrm{C}$ until analyses. The oil yield (content) was calculated as grams of oil per $100 \mathrm{~g}$ of dried oregano leaves.

Gas chromatography analysis of essential oil. Oregano essential oil samples (all in three replicates per DT) were analyzed on a Hewlett 
Packard gas chromatograph 6890 GC with an autosampler [carrier gas helium, $40 \mathrm{~cm} \cdot \mathrm{sec}^{-1}$, $11.7 \mathrm{psi}\left(60^{\circ} \mathrm{C}\right), 2.5 \mathrm{~mL} \cdot \mathrm{min}^{-1}$ constant flow rate; injection: split $60: 1,0.5 \mu \mathrm{L}$, inlet $220^{\circ} \mathrm{C}$; oven temperature program: $60^{\circ} \mathrm{C}$ for $1 \mathrm{~min}$, $10{ }^{\circ} \mathrm{C} / \min$ to $250^{\circ} \mathrm{C}$ ]. The column was HPINNOWAX (crosslinked polyethylene gly$\mathrm{col} ; 30 \mathrm{~m} \times 0.32 \mathrm{~mm} \times 0.5 \mu \mathrm{m})$ and the flame ionization detector temperature was $275^{\circ} \mathrm{C}$.

Assays for in vitro antileishmanial, antimicrobial, and antimalarial activity; assay for cytotoxicity; and antioxidant activity. Oregano essential oil from 20, 80, and $360 \mathrm{~min}$ DT was submitted for antioxidant activity by the $\mathrm{ORAC}_{\mathrm{oil}}$ method as described previously (Huang et al., 2002a, 2002b). Briefly, samples of extracted oil were prepared for antioxidant capacity tests by mixing $10 \pm 1 \mathrm{mg}$ oil with $1 \mathrm{~mL}$ of water and acetone (1:1) with 7\% methyl$\beta$-cyclodextrins (w:v). The fluorescent probe, fluorescein $\left(8.16 \times 10^{-5} \mathrm{~mm}\right)$, was incubated with different concentrations of Trolox (which served as the standard) and the oil samples for $10 \mathrm{~min}, 3 \mathrm{~min}$ of which was with shaking. After incubation, the reaction was activated by adding $153 \mathrm{~mm}$ 2,2'-azobis (2-amidinopropane) hydrochloride, i.e., the radical initiator. All samples/ standards were prepared in 96-well plates and monitored with a BMG Labtech FLUOstar Optima microplate reader (Durham, NC). Fluorescence was measured every $1.5 \mathrm{~min}$ at an excitation and emission wavelength of $485 \mathrm{~nm}$ and $520 \mathrm{~nm}$, respectively, until the decreasing fluorescence values plateaued. From these data, the area under the decay curve was calculated and the results are shown as $\mu$ mol Trolox equivalents/g of extract. Each sample was tested in triplicate.

Subsamples of bulk essential oil of oregano were screened for antileishmanial activity in vitro on a culture of Leishmania donovani promastigotes and for antimicrobial and antimalarial activities (Bharate et al., 2007).

Statistical analyses. The effect of DT on essential oil content and the concentration and yield of alpha-thujene, alpha-pinene, camphene, 1-octen-3-ol, myrcene, alpha-terpinene, paracymene, beta-phyllanderene/limonene, gamma-terpinene, cis-sabinene hydrate, terpinolene, transsabinene hydrate, borneol, 4-terpineol, carvacrol, beta-caryophylenne, betabisabolene, and paracymene was determined using a one-way analysis of variance. For each response, the validity of model assumptions

Table 1. Mean essential oil (EO) content (\%), and the concentrations (\%) of alpha-thujene, alpha-pinene, camphene, 1-octen-3-ol, and myrcene obtained from the 10 distillation times (DTs). ${ }^{\mathrm{z}}$

\begin{tabular}{clccccc}
\hline & EO yield & Alpha-thujene & Alpha-pinene & Camphene & 1-Octen-3-ol & Myrcene \\
\cline { 2 - 7 } DT (min) & \multicolumn{5}{c}{$(\%)$} \\
\hline 1.25 & $0.114 \mathrm{~h}$ & $2.2 \mathrm{a}$ & $3.36 \mathrm{a}$ & $2.18 \mathrm{a}$ & $0.87 \mathrm{a}$ & $6.06 \mathrm{a}$ \\
2.5 & $0.166 \mathrm{gh}$ & $1.9 \mathrm{~b}$ & $2.83 \mathrm{~b}$ & $1.80 \mathrm{a}$ & $0.75 \mathrm{~b}$ & $4.92 \mathrm{~b}$ \\
5 & $0.263 \mathrm{~g}$ & $1.3 \mathrm{c}$ & $1.99 \mathrm{c}$ & $1.30 \mathrm{~b}$ & $0.63 \mathrm{c}$ & $3.75 \mathrm{c}$ \\
10 & $0.404 \mathrm{f}$ & $1.0 \mathrm{~d}$ & $1.47 \mathrm{~d}$ & $0.96 \mathrm{c}$ & $0.49 \mathrm{~d}$ & $2.87 \mathrm{~d}$ \\
20 & $1.028 \mathrm{e}$ & $0.5 \mathrm{e}$ & $0.69 \mathrm{e}$ & $0.46 \mathrm{~d}$ & $0.24 \mathrm{e}$ & $1.37 \mathrm{e}$ \\
40 & $1.477 \mathrm{~d}$ & $0.2 \mathrm{f}$ & $0.35 \mathrm{f}$ & $0.24 \mathrm{e}$ & $0.13 \mathrm{f}$ & $0.73 \mathrm{f}$ \\
80 & $1.975 \mathrm{c}$ & $0.2 \mathrm{f}$ & $0.31 \mathrm{f}$ & $0.21 \mathrm{ef}$ & $0.11 \mathrm{fg}$ & $0.65 \mathrm{f}$ \\
160 & $2.022 \mathrm{c}$ & $0.2 \mathrm{f}$ & $0.29 \mathrm{f}$ & $0.20 \mathrm{ef}$ & $0.10 \mathrm{~g}$ & $0.61 \mathrm{f}$ \\
240 & $2.312 \mathrm{a}$ & $0.21 \mathrm{f}$ & $0.32 \mathrm{f}$ & $0.22 \mathrm{ef}$ & $0.09 \mathrm{~g}$ & $0.64 \mathrm{f}$ \\
360 & $2.181 \mathrm{~b}$ & $0.17 \mathrm{f}$ & $0.27 \mathrm{f}$ & $0.19 \mathrm{f}$ & $0.04 \mathrm{~h}$ & $0.58 \mathrm{f}$ \\
\hline
\end{tabular}

${ }^{2}$ Within each column, means followed by the same letter are not significantly different at $5 \%$.

was verified by examining the residuals as described in Montgomery (2009). Most of the concentration responses required cubic root transformation to meet the normality assumption. However, the means reported in the tables and figures are backtransformed values to the original scale. Because the effect of DT was significant $(P<0.05)$ on all responses, multiple means comparison was completed using Duncan's multiple range test at the 5\% level of significance and letter groupings were generated. The analysis was completed using the GLM Procedure of SAS (SAS Institute Inc., 2008).

The most appropriate model to describe the relationship between DT and all concentration response variables except betabisabolene (where there was no relationship) was the asymptotic regression model (Eq. 1). However, the relationship between DT and all yield response variables except 1-octen3-ol (where the relationship was very weak) was the Michaelis-Menten regression model (Eq. 2). Both models are nonlinear, and their parameters were estimated iteratively using the NLIN Procedure of SAS (SAS Institute Inc., 2008).

$$
\begin{aligned}
& Y=\theta_{1}-\theta_{2}\left(\exp \left(-\theta_{3} x\right)\right)+\varepsilon \\
& Y=\frac{\theta_{1} x}{\theta_{2}+x}+\varepsilon
\end{aligned}
$$

where $Y$ is the dependent (response) variable, $x$ is the independent (DT) variable, and the error term $\varepsilon$ is assumed to have normal distribution with constant variance.

\section{Results}

Effect of distillation time on oregano essential oil yield. Oregano essential oil yield (often referred to as content) ranged from $0.114 \%$ at the shortest DT to $2.3 \%$ at $240 \mathrm{~min}$ DT (Table 1). Increasing DT up to $240 \mathrm{~min}$ increased essential oil yields (Table 1; Fig. 1). Longer DT (to $360 \mathrm{~min}$ ) reduced oil yield relative to the $240 \mathrm{~min}$ but increased yield relative to the shorter DT (shorter than $240 \mathrm{~min}$ ).

Range of oil constituents and response to the distillation time. In general, the concentrations of most essential oil constituents were high at the shortest DT (1.25 or $2.5 \mathrm{~min})$, the concentrations were reduced gradually with longer DT up to $40 \mathrm{~min}$, and did not change up to the longest DT. A 10-fold concentration difference for most essential oil constituents resulted between the shortest and longest DT. However, the concentration of the major oil constituent, carvacrol, was lowest at the shortest DT (1.25 $\mathrm{min})$ and increased steadily with increase in DT up to $40 \mathrm{~min}$, where it leveled.

Alpha-thujene decreased from $2.2 \%$ at $1.25 \mathrm{~min}$ DT to $0.17 \%$ to $0.22 \%$ at 40 to 360 min DT (Table 1; Fig. 1). Alpha-pinene decreased from $3.4 \%$ at $1.25 \mathrm{~min}$ DT to $0.27 \%$ to $0.35 \%$ at 40 to $360 \mathrm{~min}$ DT. Generally, camphene was $1.8 \%$ to $2.2 \%$ at the shortest DT (1.25-2.5 min) and decreased to $\approx 0.2 \%$ at longer DT $(40-240 \mathrm{~min})$. The concentration of 1-octen-3-ol ranged from $0.87 \%$ at $1.25 \mathrm{~min}$ DT to $0.04 \%$ at $360 \mathrm{~min}$ DT with concentrations decreasing with increasing DT. Myrcene concentration was $6.06 \%$ at $1.25 \mathrm{~min}$ DT and decreased steadily with increasing DT up to $40 \mathrm{~min}$, when it plateaued at $\approx 0.58 \%$ to $0.73 \%$ of the oil (Table 1).

Alpha-terpinene was $5.1 \%$ at $1.25 \mathrm{~min}$ DT and reduced with increasing DT to $40 \mathrm{~min}$, when it leveled off at $0.64 \%$ to $0.78 \%$ (Table 2). Paracymene was $25.7 \%$ at 1.25 min DT, was reduced with increasing DT of up to $40 \mathrm{~min}$, and leveled at $2.6 \%$ to $3.3 \%$ at 40 to $360 \mathrm{~min}$ DT. Beta-phellandrene/limonene concentration was $\approx 1.9 \%$ at $1.25 \mathrm{~min}$ DT and reduced steadily with increasing DT to $40 \mathrm{~min}$; further increase in DT did not change the concentrations of these constituents. Gamma-terpinene was $19.4 \%$ at $1.25 \mathrm{~min}$ DT and reduced to $2.5 \%$ to $3 \%$ at $40-360 \mathrm{~min}$ DT. The concentration of cis-sabinene hydrate was $0.15 \%$ to $1 \%$, whereas concentration of terpineole was $0.12 \%$ to $0.85 \%$; the concentration of both constituents was highest at 1.25 to $2.5 \mathrm{~min}$ DT and reduced with increasing DT to 80 or $40 \mathrm{~min}$, respectively (Table 2 ).

With the higher boiling point constituents, the maximum concentrations shifted from 1.25 or $2.5 \mathrm{~min}$ DT to 5,10 , or $20 \mathrm{~min}$ DT (Table 3; Fig. 2). Transsabinene hydrate was highest at $0.9 \%$ to $1.0 \%$ in 1.25 to $5 \mathrm{~min}$ DT and reduced to $\approx 0.4 \%$ with increase in DT of up to $40 \mathrm{~min}$ and did not change with longer DT. Borneol and 4-terpinenol concentrations increased with increasing DT from 1.25 to $5 \mathrm{~min}$, did not change at $10 \mathrm{~min}$ DT, and then decreased again with increasing DT. Borneol ranged from $1.2 \%$ to $4 \%$, whereas 4 -terpinenol ranged from $0.94 \%$ to $2.6 \%$. The concentration of carvacrol, the major essential oil constituent, showed an opposite trend to the rest of the oil constituents with respect to response to DT. Carvacrol was $18 \%$ at $1.25 \mathrm{~min}$ DT, increased to $\approx 80 \%$ with increasing DT of up to $40 \mathrm{~min}$, and did not change with longer DT (Table 3; Fig. 2). Betacaryophyllene was $1.5 \%$ at $1.25 \mathrm{~min}$ DT, increased to $2 \%$ to $2.2 \%$ at 2.5 to $10 \mathrm{~min}$ DT, and then decreased again at $20 \mathrm{~min}$ and at $40 \mathrm{~min}$ DT. Further increase in DT did not change the concentrations relative to the $40 \mathrm{~min}$ DT. Beta bisabolene was $0.69 \%$ at 1.25 min DT, increased to $1.4 \%$ at 10 to $20 \mathrm{~min}$ DT, and decreased to reach $0.96 \%$ at $160 \mathrm{~min}$ DT. Further increase in DT actually increased it relative to the 160 min DT (Table 3; Fig. 2). 

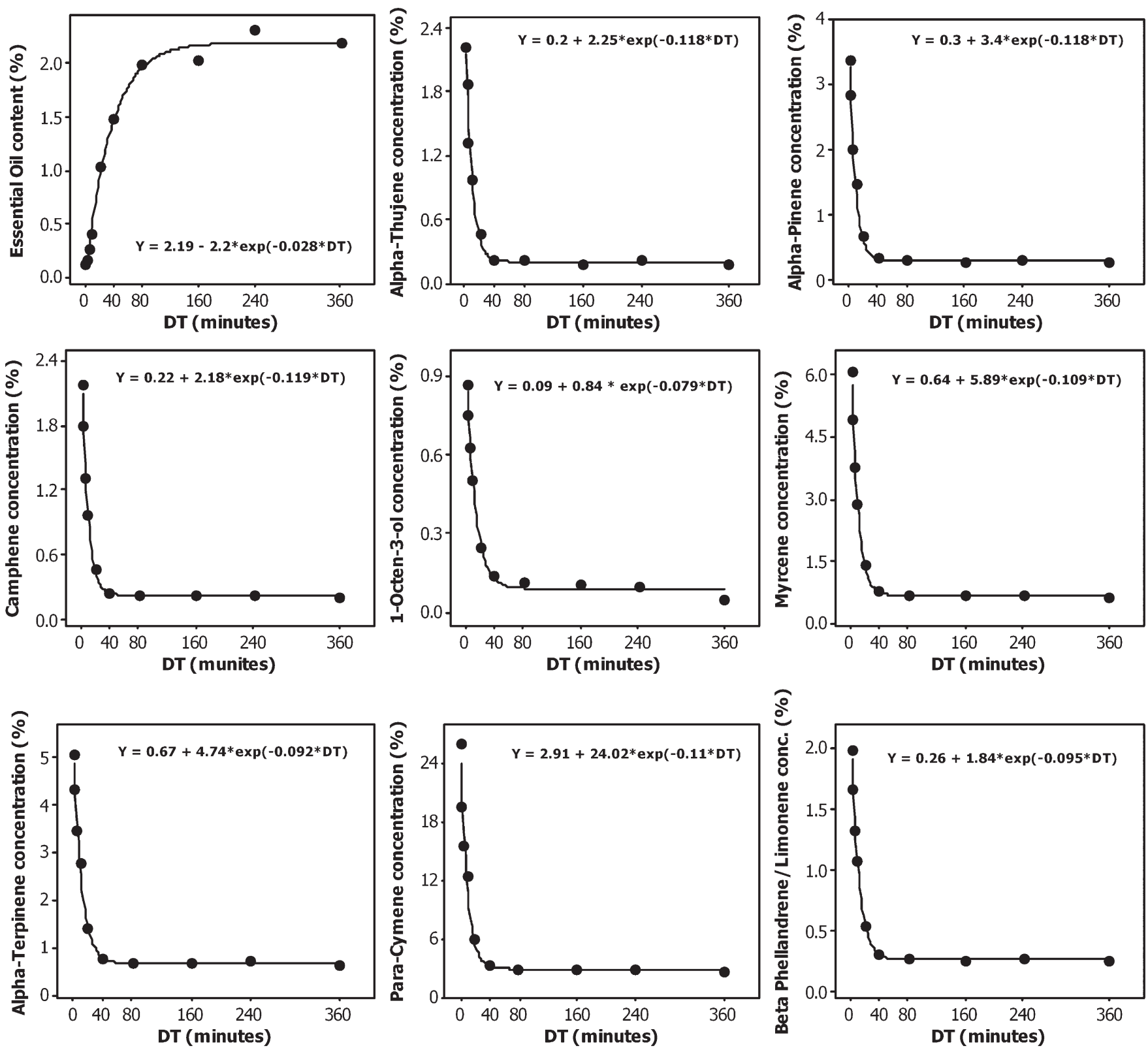

Fig. 1. Plot of essential oil content and the concentration of eight constituents vs. distillation time along with the fitted asymptotic regression model. Equations of the fitted models are shown within each plot.

Table 2. Mean concentrations (\%) of alpha-terpinene, para-cymene, beta-phellandrene/limonene, gamma-terpinene, cis-sabinene hydrate, and terpinolene obtained from the 10 distillation times (DTs). ${ }^{\mathrm{z}}$

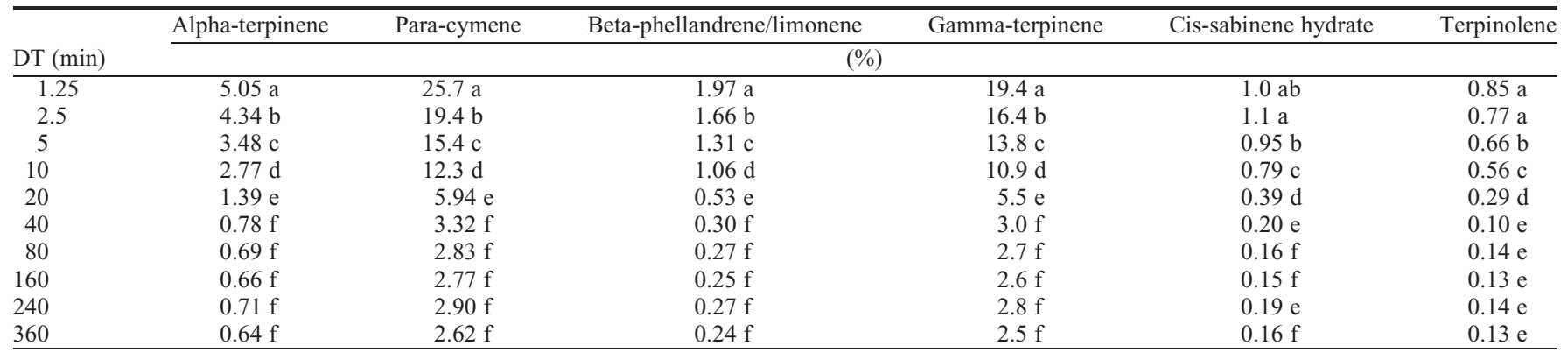

${ }^{2}$ Within each column, means followed by the same letter are not significantly different at $5 \%$.

Yield of essential oil constituents. The yield of essential oil constituents indicates how much of the individual constituent was actually extracted at different DT and was calculated HortScience Vol. 47(6) June 2012 from the essential oil yield and the concentration of individual oil constituents at any given DT. Overall, the yields of the oil constituents were lowest at the shortest DT and increased with increasing DT (Tables 4, 5, and 6; Figs. 3 and 4). Maximum yield of the low boiling constituents alpha-thujene, alpha-pinene, camphene, and myrcene was achieved at relatively 
short DT, at $\approx 20 \mathrm{~min}$ DT, and then peaked again at 240 min DT (Table 4; Fig. 3). The yield of 1-octen-3-ol was also maximized at 20 min DT; further increase in DT reduced the yield relative to the one at 20 min DT (Table 4). Yields of all of these constituents at 360 min DT were lower than the ones at $240 \mathrm{~min}$ DT.
The yields of alpha-terpinene, betaphellandrene/limonene, and gamma-terpinene increased with increasing DT and reached maximum at $240 \mathrm{~min}$ DT; yields at $360 \mathrm{~min}$

Table 3. Mean concentrations (\%) of transsabinene hydrate, borneol, 4-terpinenol, carvacrol, beta-caryophyllene, and beta-bisabolene obtained from the 10 distillation times (DTs). ${ }^{z}$

\begin{tabular}{|c|c|c|c|c|c|c|}
\hline DT (min) & Transsabinene hydrate & Borneol & 4-Terpinenol & Carvacrol & Beta-caryophyllene & Beta-bisabolen \\
\hline 2.5 & $1.06 \mathrm{a}$ & $3.24 \mathrm{~b}$ & $2.10 \mathrm{~b}$ & $27.7 \mathrm{e}$ & $2.07 \mathrm{a}$ & $0.99 \mathrm{~cd}$ \\
\hline 5 & $0.97 \mathrm{ab}$ & $3.77 \mathrm{a}$ & $2.39 \mathrm{a}$ & $37.4 \mathrm{~d}$ & $2.20 \mathrm{a}$ & $1.28 \mathrm{~b}$ \\
\hline 20 & $0.75 \mathrm{c}$ & $2.58 \mathrm{c}$ & $1.68 \mathrm{c}$ & $68.2 \mathrm{~b}$ & $1.33 \mathrm{~b}$ & $1.49 \mathrm{a}$ \\
\hline 40 & $0.40 \mathrm{~d}$ & $1.64 \mathrm{~d}$ & $1.17 \mathrm{e}$ & $79.5 \mathrm{a}$ & $0.90 \mathrm{c}$ & $1.10 \mathrm{bcd}$ \\
\hline 80 & $0.32 \mathrm{~d}$ & $1.29 \mathrm{de}$ & $0.95 \mathrm{f}$ & $81.8 \mathrm{a}$ & $0.77 \mathrm{c}$ & $1.00 \mathrm{~cd}$ \\
\hline 360 & $0.31 \mathrm{~d}$ & $1.30 \mathrm{de}$ & $1.01 \mathrm{f}$ & $81.8 \mathrm{a}$ & $0.85 \mathrm{c}$ & $1.18 \mathrm{bc}$ \\
\hline
\end{tabular}

${ }^{\mathrm{z}}$ Within each column, means followed by the same letter are not significantly different at $5 \%$.
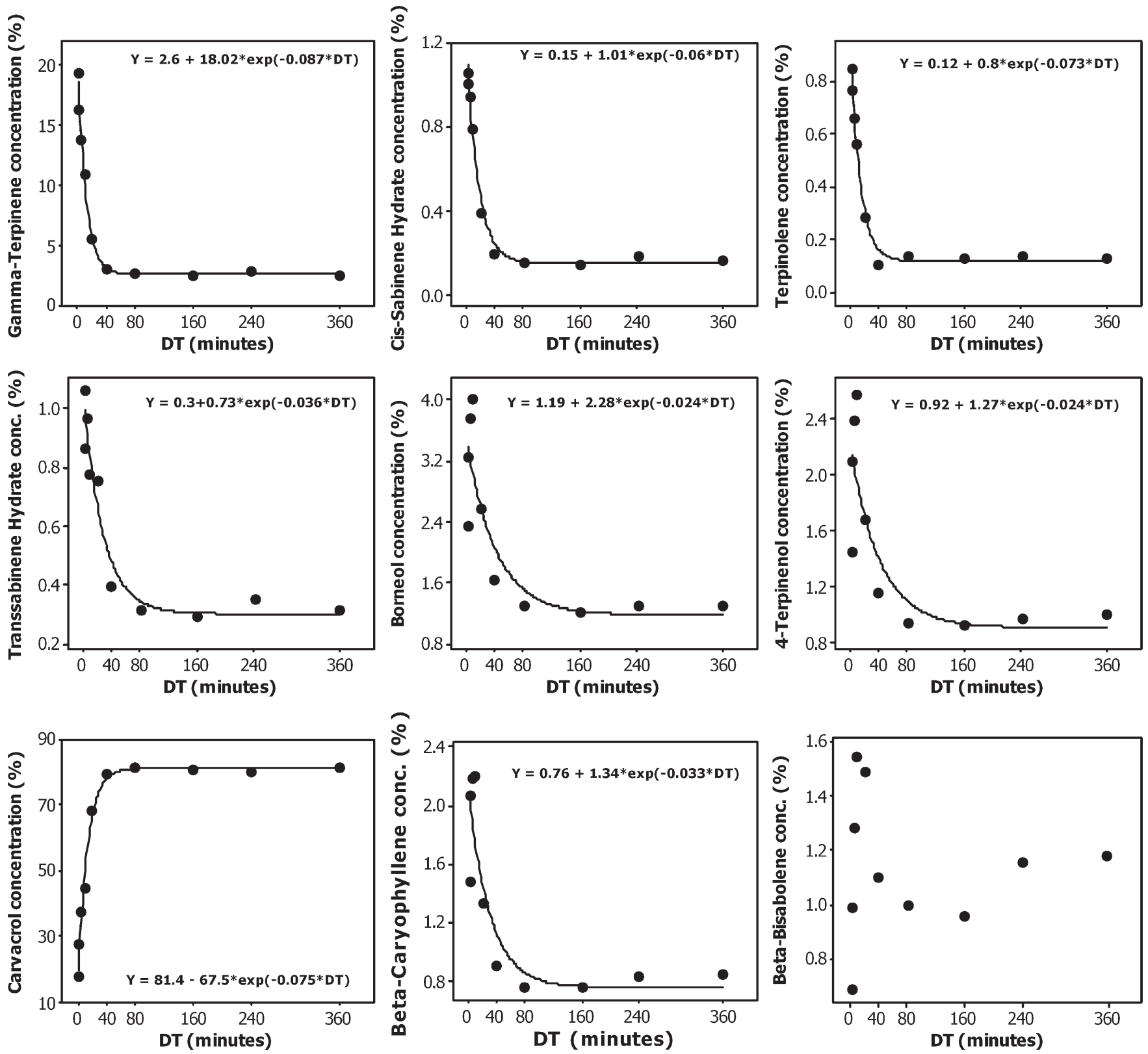

Fig. 2. Plot of the concentration of nine constituents vs. distillation time along with the fitted asymptotic regression model. Equations of the fitted models are shown within each plot. Because there was no significant relationship for beta-bisabolene, only the scatterplot is shown. 
Table 4. Mean yields (mg) of alpha-thujene, alpha-pinene, camphene, 1-octen-3-ol, and myrcene obtained from the 10 distillation times (DTs). ${ }^{\mathrm{z}}$

\begin{tabular}{|c|c|c|c|c|c|}
\hline \multirow[b]{2}{*}{ DT (min) } & Alpha-thujene & Alpha-pinene & Camphene & 1-Octen-3-ol & Myrcene \\
\hline & \multicolumn{5}{|c|}{$(\mathrm{mg})$} \\
\hline 1.25 & $2.54 \mathrm{e}$ & $3.86 \mathrm{~d}$ & $2.51 \mathrm{f}$ & $1.04 \mathrm{ef}$ & $6.98 \mathrm{f}$ \\
\hline 2.5 & $3.11 \mathrm{de}$ & $4.68 \mathrm{~cd}$ & $2.99 \mathrm{ef}$ & $1.24 \mathrm{e}$ & 8.17 ef \\
\hline 5 & $3.47 \mathrm{~cd}$ & $5.23 \mathrm{bc}$ & $3.42 \mathrm{de}$ & $1.65 \mathrm{~d}$ & $9.86 \mathrm{de}$ \\
\hline 10 & $3.79 \mathrm{~cd}$ & $5.71 \mathrm{bc}$ & $3.79 \mathrm{~cd}$ & $2.18 \mathrm{~b}$ & $11.3 \mathrm{~cd}$ \\
\hline 20 & $4.77 \mathrm{ab}$ & $7.09 \mathrm{a}$ & $4.77 \mathrm{ab}$ & $2.46 \mathrm{a}$ & $14.1 \mathrm{ab}$ \\
\hline 40 & $3.24 \mathrm{cde}$ & $5.10 \mathrm{bc}$ & $3.48 \mathrm{de}$ & $1.92 \mathrm{c}$ & $10.7 \mathrm{~cd}$ \\
\hline 80 & $4.04 \mathrm{bc}$ & $6.01 \mathrm{~b}$ & $4.24 \mathrm{bc}$ & $2.17 \mathrm{~b}$ & $12.8 \mathrm{abc}$ \\
\hline 160 & $3.71 \mathrm{~cd}$ & $5.87 \mathrm{~b}$ & $4.11 \mathrm{bcd}$ & $2.02 \mathrm{bc}$ & $12.3 \mathrm{bc}$ \\
\hline 240 & $4.86 \mathrm{a}$ & $7.48 \mathrm{a}$ & $5.09 \mathrm{a}$ & $2.15 \mathrm{~b}$ & $14.9 \mathrm{a}$ \\
\hline 360 & $3.73 \mathrm{~cd}$ & $5.92 \mathrm{~b}$ & $4.09 \mathrm{bcd}$ & $0.87 \mathrm{f}$ & $12.6 \mathrm{bc}$ \\
\hline
\end{tabular}

${ }^{\mathrm{z}}$ Within each column, means followed by the same letter are not significantly different at $5 \%$.

Table 5. Mean yields (mg) of alpha-terpinene, para-cymene, beta-phellandrene/limonene, gamma-terpinene, cis-sabinene hydrate, and terpinolene obtained from the 10 distillation times (DTs). ${ }^{\mathrm{z}}$

\begin{tabular}{|c|c|c|c|c|c|c|}
\hline \multirow[b]{2}{*}{ DT (min) } & Alpha-terpinene & Para-cymene & Beta-phellandrene/limonene & Gamma-terpinene & Cis-sabinene hydrate & Terpinolene \\
\hline & \multicolumn{6}{|c|}{$(\mathrm{mg})$} \\
\hline 1.25 & $5.80 \mathrm{e}$ & $29.8 \mathrm{f}$ & $2.26 \mathrm{e}$ & $22.3 \mathrm{e}$ & $1.15 \mathrm{~g}$ & $0.97 \mathrm{~g}$ \\
\hline 2.5 & $7.21 \mathrm{e}$ & $32.3 \mathrm{f}$ & $2.75 \mathrm{e}$ & $27.3 \mathrm{e}$ & $1.76 \mathrm{f}$ & $1.27 \mathrm{f}$ \\
\hline 5 & $9.14 \mathrm{~d}$ & $40.4 \mathrm{e}$ & $3.44 \mathrm{~d}$ & $36.2 \mathrm{~d}$ & $2.48 \mathrm{e}$ & $1.74 \mathrm{e}$ \\
\hline 10 & $10.9 \mathrm{~cd}$ & $48.1 \mathrm{de}$ & $4.16 \mathrm{c}$ & $43.0 \mathrm{~cd}$ & $3.16 \mathrm{~cd}$ & $2.19 \mathrm{~d}$ \\
\hline 20 & $14.3 \mathrm{~b}$ & $60.9 \mathrm{ab}$ & $5.46 \mathrm{~b}$ & $56.5 \mathrm{~b}$ & $3.97 \mathrm{ab}$ & $2.97 \mathrm{ab}$ \\
\hline 40 & $11.4 \mathrm{c}$ & $49.0 \mathrm{~cd}$ & $4.47 \mathrm{c}$ & $44.7 \mathrm{c}$ & $2.95 \mathrm{de}$ & $2.12 \mathrm{~d}$ \\
\hline 80 & $13.7 \mathrm{~b}$ & $55.7 \mathrm{bcd}$ & $5.32 \mathrm{~b}$ & $53.5 \mathrm{~b}$ & $3.16 \mathrm{~cd}$ & $2.66 \mathrm{c}$ \\
\hline 160 & $13.4 \mathrm{~b}$ & $56.1 \mathrm{bcd}$ & $5.12 \mathrm{~b}$ & $51.9 \mathrm{~b}$ & $2.97 \mathrm{de}$ & $2.63 \mathrm{c}$ \\
\hline 240 & $16.4 \mathrm{a}$ & $66.9 \mathrm{a}$ & $6.16 \mathrm{a}$ & $63.9 \mathrm{a}$ & $4.39 \mathrm{a}$ & $3.16 \mathrm{a}$ \\
\hline 360 & $14.1 \mathrm{~b}$ & $57.5 \mathrm{bc}$ & $5.32 \mathrm{~b}$ & $54.5 \mathrm{~b}$ & $3.57 \mathrm{bc}$ & $2.77 \mathrm{bc}$ \\
\hline
\end{tabular}

${ }^{\mathrm{z}}$ Within each column, means followed by the same letter are not significantly different at $5 \%$.

Table 6. Mean yields (mg) of transsabinene hydrate, borneol, 4-terpinenol, carvacrol, beta-caryophyllene, and beta-bisabolene obtained from the 10 distillation times (DTs). ${ }^{\mathrm{z}}$

\begin{tabular}{|c|c|c|c|c|c|c|}
\hline & Transsabinene hydrate & Borneol & 4-Terpinenol & Carvacrol & Beta-caryophyllene & Beta-bisabolene \\
\hline DT (min) & \multicolumn{6}{|c|}{ (mg) } \\
\hline 1.25 & $0.97 \mathrm{f}$ & $2.6 \mathrm{~g}$ & $1.6 \mathrm{f}$ & $20 \mathrm{f}$ & $1.68 \mathrm{~g}$ & $0.77 \mathrm{f}$ \\
\hline 2.5 & $1.77 \mathrm{e}$ & $5.4 \mathrm{f}$ & $3.5 \mathrm{e}$ & $46 \mathrm{f}$ & $3.44 \mathrm{f}$ & $1.65 \mathrm{ef}$ \\
\hline 5 & $2.54 \mathrm{~d}$ & $9.9 \mathrm{e}$ & $6.3 \mathrm{~d}$ & 99 ef & $5.78 \mathrm{e}$ & $3.40 \mathrm{e}$ \\
\hline 10 & $3.08 \mathrm{~d}$ & $18.9 \mathrm{~d}$ & $11.9 \mathrm{c}$ & $187 \mathrm{e}$ & $9.76 \mathrm{~d}$ & $7.35 \mathrm{~d}$ \\
\hline 20 & $7.72 \mathrm{a}$ & $26.4 \mathrm{bc}$ & $17.2 \mathrm{~b}$ & $703 \mathrm{~d}$ & $13.7 \mathrm{c}$ & $15.3 \mathrm{c}$ \\
\hline 40 & $5.85 \mathrm{c}$ & $24.2 \mathrm{c}$ & $17.2 \mathrm{~b}$ & $1175 \mathrm{c}$ & $13.3 \mathrm{c}$ & $16.3 \mathrm{c}$ \\
\hline 80 & $6.21 \mathrm{bc}$ & $25.5 \mathrm{c}$ & $18.7 \mathrm{~b}$ & $1615 \mathrm{~b}$ & $15.1 \mathrm{~b}$ & $19.7 \mathrm{~b}$ \\
\hline 160 & $5.93 \mathrm{c}$ & $24.7 \mathrm{c}$ & $18.9 \mathrm{~b}$ & $1631 \mathrm{~b}$ & $15.3 \mathrm{~b}$ & $19.4 \mathrm{~b}$ \\
\hline 240 & $8.16 \mathrm{a}$ & $30.0 \mathrm{a}$ & $22.5 \mathrm{a}$ & $1848 \mathrm{a}$ & $19.1 \mathrm{a}$ & $26.8 \mathrm{a}$ \\
\hline 360 & $6.83 \mathrm{~b}$ & $28.3 \mathrm{ab}$ & $22.0 \mathrm{a}$ & $1782 \mathrm{a}$ & $18.5 \mathrm{a}$ & $25.7 \mathrm{a}$ \\
\hline
\end{tabular}

${ }^{\mathrm{z}}$ Within each column, means followed by the same letter are not significantly different at $5 \%$.

DT were lower than the ones at 240 min DT (Table 5). Overall, maximum yields of paracymene, cys-sabinene hydrate, terpinolene, and transsabinene hydrate were achieved at $240 \mathrm{~min}$ DT, but yields at $20 \mathrm{~min}$ DT time were not different from the ones at $240 \mathrm{~min}$ DT (Tables 5 and 6). Yields of these four constituents at 360 min DT were lower than the ones at 240 min DT. Yields of borneol, 4-terpinenol, carvacrol, beta-caryophyllene, and beta-bisabolene were maxed at $240 \mathrm{~min}$ DT; further increase of DT did not decrease the yields relative to the $240 \mathrm{~min}$ DT (Table 6; Fig. 4).

Antioxidant activity of oils from various distillation times and antimicrobial activity of bulk oil. Oregano oils from the 20,80, and $360 \mathrm{~min}$ did not differ in antioxidant activity (with averages 60.8, 74.5, and $60.4 \mu \mathrm{mol}$ Trolox equivalents/g, respectively). Additionally, bulk oregano oils at $50.0 \mu \mathrm{g} \cdot \mathrm{mL}^{-1}$ did not have significant antimicrobial, antileishmanial, or antimalarial activity at concentrations that would warrant bioassay-directed fractionation in a drug-discovery screening program as established by the National Center for Natural Products Research in Oxford, MS. Oregano essential oil showed lower than $50 \%$ growth inhibition of Leishmania donovani, Plasmodium falciparum clones D6 and W2, Candida krusei (6\% inhibition), Candida glabrata (3\% inhibition), Escherichia coli (6\% inhibition), Pseudomonas aeruginosa, Cryptococcus neoformans ( $8 \%$ inhibition), Mycobacterium intracellulare (4\% inhibition), or Aspergillus fumigatus (5\% inhibition) at $50 \mu \mathrm{g} \cdot \mathrm{mL}^{-1}$.

Nonlinear regression modeling results. The fitted nonlinear regression models shown in Figures 1 and 2 suggest that the relationship between DT and essential oil content as well as the concentration of the constituents can be modeled by the asymptotic regression model (Eq. 1) almost perfectly, except for the concentration of beta-bisabolene where there was no relationship (Fig. 2). The fitted models shown within each plot can be used to predict essential oil content and the concentration of the constituents at any given DT. On the other hand, the best nonlinear regression model that describes the relationship between yield of the constituents and DT was the Michaelis-Menten regression model (Figs. 3 and 4). However, because the fits were not as perfect as those for concentration, these models should be used with caution for prediction purposes.

\section{Discussion and Concluding Remarks}

Indeed, various researchers reported different DTs such as $60 \mathrm{~min}$ (Tekippe et al., 2011), $120 \mathrm{~min}$ (Bisht et al., 2009; Farías et al., 2010), or $180 \mathrm{~min}$ (Azizi et al., 2009; Sotiropoulou and Karamanos, 2010). However, it was not known how the results from 

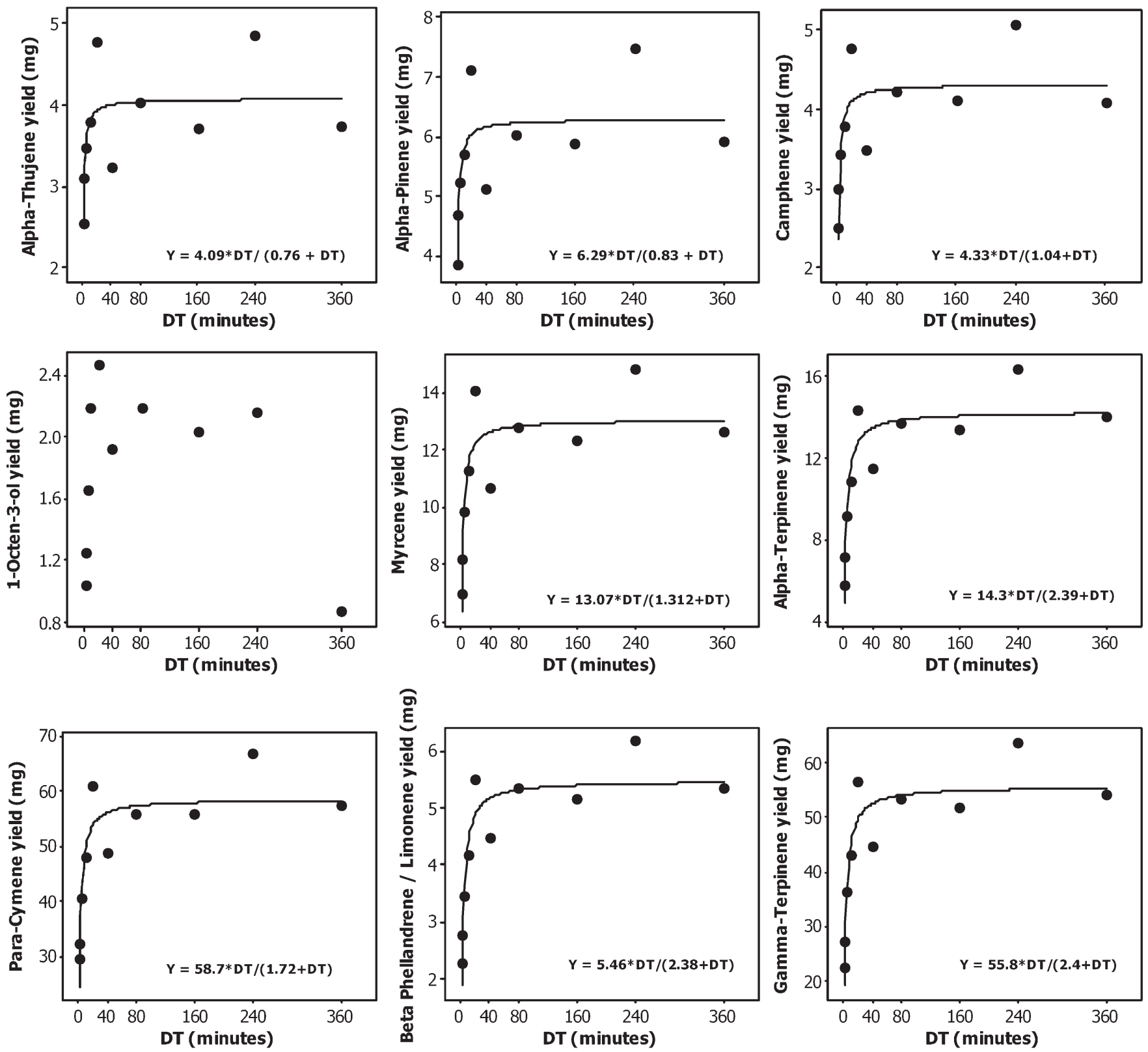

Fig. 3. Plot of the yields of nine constituents vs. distillation time along with the fitted Michaelis-Menten regression model. Equations of the fitted models are shown within each plot. Because there was no significant relationship for 1-octen-3-ol, only the scatterplot is shown.

various reports using different DTs compare, and there was no comprehensive study on the effect of DT on oregano essential oil yield and composition. This study demonstrated that maximum essential oil yields from dried oregano leaves can be achieved at $240 \mathrm{~min}$ DT. This study also demonstrated that DT has a significant effect on the concentration and yields of the essential oil constituents. The concentration of carvacrol, the major oil constituent, continued to increase with increasing DT up to $240 \mathrm{~min}$. Shorter DT resulted in much lower carvacrol concentrations. Most other oil constituents had higher concentrations at the shorter DT ( 1.25 to $5 \mathrm{~min})$ and then decreased, but their yield actually increased with increasing DT. The increase in the yield of essential oil constituents suggests there were no conversions or other losses of any given oil constituent during the distillation process. With the exception of beta-bisabolene concentration, the changes in essential oil yield (content) and the concentration of the constituents as a function of DT can be modeled and predicted almost perfectly by the asymptotic regression model. However, this is not quite true for the yield of the constituents.

The results on antimicrobial activity of oregano essential oil contradict previous reports (Karakaya et al., 2011) that reported inhibition of Listeria monocytogenes, Salmonella typhimurium, and E. coli. The lack of significant antimicrobial activity of oregano oil tested in this study might be the result of dissimilar methods or higher concentrations used in the reported studies relative to our study where concentrations of $50 \mu \mathrm{g} \cdot \mathrm{mL}^{-1}$ were used.
Although published reports on the lipophilic antioxidant capacity of oregano are limited, the values obtained in this study are within the range of many herbs and spices (Jimenez-Alverez et al., 2008; U.S. Department of Agriculture, 2010). Considering that essential oils are currently being linked to multiple health benefits and preservation qualities as a result of their ability to protect against oxidation, optimizing a lipophilic extraction process for both compositional and total oil levels is needed to ensure consistent antioxidant capacities (Bakkali et al., 2008; Sacchitti et al., 2005). The similar antioxidant values (on a per-gram basis) for the oregano oils collected at time points throughout the DT range $(20,80$, and $360 \mathrm{~min})$ further indicate that any given oil-based antioxidant was not converted or lost during the distillation process. 

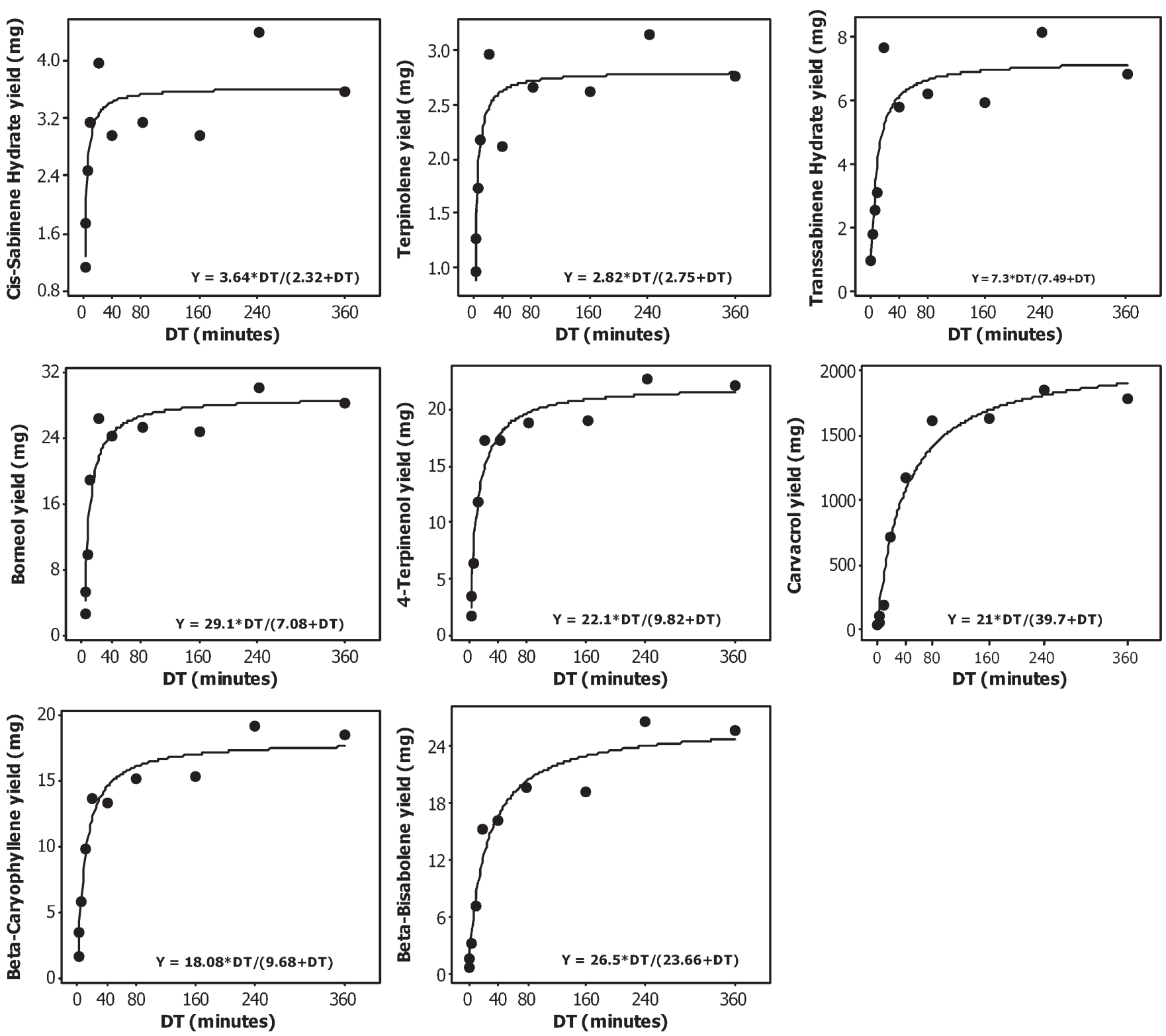

Fig. 4. Plot of the yields of eight constituents vs. distillation time along with the fitted Michaelis-Menten regression model. Equations of the fitted models are shown within each plot.

However, the total amount of antioxidant agents also increased with higher oil yields supporting the application of longer DT to oregano-based oil extractions.

This study suggests that comparing essential oil yield and composition between different reports must take into consideration the length of the steam distillation.

\section{Literature Cited}

Atanassova, M. and N. Nedkov. 2004. Essential oil and medicinal crops. Kameja Press, Sofia, Bulgaria.

Azizi, A., Y. Feng, and B. Honermeier. 2009. Herbage yield, essential oil content and composition of three oregano (Origanum vulgare L.) populations as affected by soil moisture regimes and nitrogen supply. Ind. Crops Prod. 29:554-561.

Bakkali, F., S. Averbeck, D. Averbeck, and M. Idaomar. 2008. Biological effects of essential oils-A review. Food Chem. Toxicol. 46:446-475.
Bharate, S.B., S.I. Khan, N.A. Yunus, S.K. Chauthe, M.R. Jacob, B.L. Tekwani, I.A. Khan, and I.P. Singh. 2007. Antiprotozoal and antimicrobial activities of O-alkylated and formylated acylphloroglucinols. Bioorg. Med. Chem. 15:87-96.

Bisht, D., C.S. Chanotiy, M. Rana, and M. Semwal. 2009. Variability in essential oil and bioactive chiral monoterpenoid compositions of Indian oregano (Origanum vulgare L.) populations from northwestern Himalaya and their chemotaxonomy. Ind. Crops Prod. 30:422-426.

Busatta, C., A.J. Mossi, M.R.A. Rodrigues, R.L. Cansian, and J.V. de Oliveira. 2007. Evaluation of Origanum vulgare essential oil as antimicrobial agent in sausage. Braz. J. Microbiol. 38:610616.

Farías, G., O. Brutti, R. Grau, P. Di Leo Lira, D. Rettad, C. van. Baren, S. Vento, and A.L. Bandoni. 2010. Morphological, yielding and quality descriptors of four clones of Origanum spp. (Lamiaceae) from the Argentine Littoral region Germplasm bank. Ind. Crops Prod. 32: 472-480.
Gaspar, F. and G. Leeke. 2004. Comparison between compressed $\mathrm{CO}_{2}$ extracts and hydrodistilled essential oil. J. Essent. Oil Res. 16: 64-68.

Huang, D., B. Ou, M. Hampsch-Woodill, J. Flanagan, and E.K. Demmer. 2002a. Development and validation of oxygen radical absorbance capacity assay for lipophilic antioxidants using randomly methylate B-cylodextrin as the solubility enhancer. J. Agr. Food Chem. 50:1815-1821.

Huang, D., B. Ou, M. Hampsch-Woodill, J. Flanagan, and R. Prior. 2002b. High-throughput assay of oxygen radical absorbance capacity (ORAC) using a multichannel liquid handling system coupled with a microplate fluorescence reader in 96-well format. J. Agr. Food Chem. 50:44374444.

Jimenez-Alvarez, D., F. Giuffrida, P.A. Goay, C. Cotting, A. Lardau, and B.J. Keely. 2008. Antioxidant activity of oregano, parsley, and olive mill wastewaters in bulk oils and oil in water emulsion enriched in fish oil. J. Agr. Food Chem. 56:7151-7159. 
Kula, J., T. Majda, A. Stoyanova, and E. Georgiev. 2007. Chemical composition of Origanum vulgare L. essential oil from Bulgaria. J. Essent. Oil Bear. Plants. 10:215-220.

Karakaya, S., El, S.N. Karagözlü, and S. Sahin. 2011. Antioxidant and antimicrobial activities of essential oils obtained from oregano (Origanum vulgare ssp. hirtum) by using different extraction methods. J. Med. Food 14(6):645652.

Montgomery, D.C. 2009. Design and analysis of experiments. 7th Ed. Wiley, New York, NY.

Ntzimani, A.G., V.I. Giatrakou, and I.N. Savvaidis. 2011. Combined natural antimicrobial treatments on a ready-to-eat poultry product stored at 4 and $8^{\circ}$ C. Poult. Sci. 90:880-888.

Ondarza, M. and A. Sánchez. 1990. Steam distillation and supercritical fluid extraction of some Mexican spices. Chromatographia 30:16-18.

Roussenova, N.V. 2011. Antibacterial activity of essential oils against the etiological agent of
American foulbrood disease (Paenibacillus larvae). Bulg. J. Vet. Med. 1:17-24.

Sacchitti, G., S. Maietti, M. Muzzoil, S. Manfedini, M. Radice, and R. Bruni. 2005. Comparative evaluation of 11 essential oils of different origin as functional antioxidants, antiradicals, and antimicrobials in foods. Food Chem. 91:621-632.

SAS Institute Inc. 2008. SAS/STAT ${ }^{\circledR} 9.2$ user's guide. SAS Institute Inc., Cary, NC.

Sotiropoulou, D.E. and A.J. Karamanos. 2010 Field studies of nitrogen application on growth and yield of Greek oregano [Origanum vulgare ssp. hirtum (Link) Ietswaart]. Ind. Crops Prod. 32:450-457.

Stojanov, N.S. 1973. Our medicinal plants. Part II. Nauka and Izkustvo (Science and Art) Press, Sofia, Bulgaria.

Tekippe, J.A., A.N. Hristov, K.S. Heyler, T.W. Cassidy, V.D. Zheljazkov, J.F.S. Ferreira, S.K. Karnati, and G.A. Varga. 2011. Rumen fermentation and production effects of Origanum vulgare L. in lactating dairy cows. J. Dairy Sci. 94:5065-5079.

Topalov, V.D. 1962. Essential oil and medicinal plants. Hr. G. Danov Press, Plovdiv, Bulgaria.

U.S. Department of Agriculture. 2010. Oxygen radical absorbance capacity (ORAC) of selected foods-release 2. 28 Apr. 2012. <http:// www.ars.usda.gov/nutrientdata>.

Yanishlieva, N.V., E. Marinova, and J . Pokorný. 2006. Natural antioxidants from herbs and spices. Eur. J. Lipid Sci. Technol. 108:776793.

Zheljazkov, V.D. and T. Astatkie. 2011. Effect of residual distillation water of 15 plants and three plant hormones on Scotch spearmint (Mentha $\times$ gracilis Sole). Ind. Crops Prod. 33:704-709.

Zheljazkov, V.D., C.L. Cantrell, T. Astatkie, and A. Hristov. 2010. Yield, content, and composition of peppermint and spearmints as a function of harvesting time and drying. J. Agr. Food Chem. 58:11400-11407. 